\title{
Organochlorine pesticides in soil under irrigated cotton farming systems in Vertisols of the Namoi valley, north-western New South Wales, Australia
}

\author{
T. B. Weaver ${ }^{1,2}$ H. Ghadiri ${ }^{2}$, N.R. Hulugalle ${ }^{1,4}$ and S. Harden ${ }^{3}$ \\ ${ }^{1}$ Australian Cotton Research Institute, NSW Department of Primary Industries, Narrabri, NSW 2390 \& Cotton \\ Catchment Communities Co-operative Research Centre \\ ${ }^{2}$ School of Environment, Griffith University, Nathan, Qld 4111 \\ ${ }^{3}$ Tamworth Agricultural Institute, NSW Department of Primary Industries, Calala, NSW 2340 \\ ${ }^{4}$ Corresponding author. Tel: 61-2-67991533; Fax: 61-2-67991503; Email: nilantha.hulugalle@dpi.nsw.gov.au
}

\begin{abstract}
Organochlorine pesticides (OCPs) such as DDT and DDE have been detected in the surface $0.2 \mathrm{~m}$ of Vertisols in the lower Namoi Valley of north western New South Wales, Australia even though they have not been applied to crops since 1982. However, their presence in the deeper soil horizons has not been investigated. The objective of this study was to determine if OCPs were present to a depth of $1.2 \mathrm{~m}$ in Vertisols under irrigated cotton farming systems in the lower Namoi Valley of New South Wales. Soil was sampled from the 0-1.2 m depths in three sites, viz. the Australian Cotton Research Institute, ACRI, near Narrabri (149 $\left.36^{\prime} \mathrm{E}, 30^{\circ} 12^{\prime} \mathrm{S}\right)$, and two cotton farms near Wee Waa $\left(149^{\circ} 27^{\prime} \mathrm{E}, 30^{\circ} 13^{\prime} \mathrm{S}\right)$ and Merah North $\left(149^{\circ} 18^{\prime} \mathrm{E}, 30^{\circ} 12^{\prime} \mathrm{S}\right)$ in northern New South Wales, Australia. The OCPs detected and their metabolites were $\alpha$-endosulfan, $\beta$-endosulfan, endosulfan sulphate, DDD, DDE, DDT and endrin. The metabolite DDE, a breakdown product of DDT, was the most persistent OCP in all depths analysed. Endosulfan sulphate was the second most persistent followed by endrin $>\alpha$-endosulfan $>\beta$-endosulfan $>$ DDT and DDD. DDT was sprayed extensively in the lower Namoi Valley up to the early 1980's and may explain the persistence of DDE in the majority of soil samples. Dicofol and Dieldrin, two OCPs previously undocumented in Vertisols were also detected. The movement of OCPs into the subsoil of Vertisols may occur when irrigation or rain
\end{abstract}


transports soil colloids and organic matter via preferential flow systems into the deeper layers of a soil profile. Persistence of OCPs was closely correlated to soil organic carbon concentrations. The persistence in soil of OCP's applied to cotton crops grown more than two decades ago suggests that they could enter the food chain. Their presence at depths of $1.2 \mathrm{~m}$ suggests that they could move into groundwater that may eventually be used for domestic and stock consumption.

\section{Keywords}

Cotton, Preferential flow, Clay, Farming system, Drainage, Rotation, Semi-arid

\section{Introduction}

Organochlorine pesticides (OCPs) such as DDT (dichlorodiphenyltrichloroethane) and its metabolites such as DDE (dichlorodiphenylethane) at concentrations ranging from 0 to $2 \mathrm{mg} / \mathrm{kg}$ have been detected in the surface $0.2 \mathrm{~m}$ of Vertisols (> $50 \mathrm{~g} / 100 \mathrm{~g}$ clay) in the lower Namoi Valley of north western New South Wales, Australia (Shivaramaiah et al., 2002). The last applications of DDT in the region are thought to have taken place in 1982 when endosulfan was introduced and DDT was banned (Shivaramaiah et al., 2002). At the same time, significant amounts of seasonal deep drainage have been reported in these same soils (Silburn and Montgomery, 2004; Weaver et al., 2005; Ringrose-Voase and Nadelko, 2010). It is likely, therefore, that OCPs are present below $0.2 \mathrm{~m}$ in the soil profile and are accumulating at depth with the potential to move into shallow groundwater systems.

The literature indicates that there are few studies which have assessed the presence and concentrations of OCPs in the deeper soil horizons and none that have addressed these issues in clayey Vertisols. A study conducted on the outskirts of Beijing, China, found that DDE was present to a depth of $1.8 \mathrm{~m}$ (<32 g/100 g clay) with concentrations ranging from 0.05 to $48 \mu \mathrm{g} / \mathrm{kg}$ (Zhu et. al., 2005). Other studies from China (Feng et al., 2003) reported DDT and HCH values ranging from 0 to $4 \mu \mathrm{g} / \mathrm{kg}$ in the $0.16-0.30 \mathrm{~m}$ depth and 0 to $3 \mu \mathrm{g} / \mathrm{kg}$ in the $0.31-0.50 \mathrm{~m}$ depths. In a survey of upland (not defined by authors; presumably hill country pasture), rainfed cropping and lowland paddy soils, Zhang et al. (2009) reported that the concentrations of DDT and its breakdown products 
such as DDE ranged from 0.5 to $484 \mu \mathrm{g} / \mathrm{kg}$ and $\mathrm{HCH}$ from 0.3 to 18 in the $0-1 \mathrm{~m}$ depth with a greater proportion (60-80\%) occurring in the subsoil. Highest values of DDT were observed in cotton soils and $\mathrm{HCH}$ in rice paddy soils. In general, where the subsoil has been studied, OCPs such as DDT have been detected at concentrations ranging from 0 to $\sim 200 \mu \mathrm{g} / \mathrm{kg}$ (Zhu et. al., 2005; Feng et al., 2003; Zhang et al, 2006, 2009; Gonzalez et al., 2010), although higher concentrations were detected in areas that had been subjected to higher rates of application (Zhang et al., 2009).

OCPs are also known to be recalcitrant to degradation in natural environments and are, thus, persistent organic pollutants (Zhang et. al., 2006). In strongly-aggregated clay soils such as Vertisols, the OCPs may be further protected from degradation by aggregation around organic matter to which the OCPs are adsorbed. The consequent impacts of these OCPs that have been stored for lengthy periods in the subsoil on the environment and human health has not been determined.

The objective of this study was to determine if OCPs were present to a depth of $1.2 \mathrm{~m}$ in the soil fraction of Vertisols under irrigated cotton farming systems in the lower Namoi Valley of New South Wales. Soil rather than leachate collected from soil water samplers was preferred because review of the literature indicated that OCPs are hydrophobic but are strongly adsorbed to soil organic carbon (Meijer et al., 2003; Cornejo et al., 2005). Hence, transport of OCPs occurs primarily by physical movement of soil particles during rain and irrigation events along preferential flow channels or by matric flow (Haria et al., 1994; Favre et al., 1997; Zhang et al., 2009) rather than through dissolution or as a suspension in water. In swelling soil such as Vertisols, other pathways such as dry soil falling down deep cracks (Hulugalle et al., 2001) and soil "churning” or inversion during wetting/drying cycles (Cheng and Petty, 1993; Kishne et al., 2009) may also be involved. Laser levelling and soil inversion during land preparation may be another pathway.

\section{Materials and methods}

\subsection{Experimental sites and soil sampling}


Soil was sampled from the 0-1.2 $\mathrm{m}$ depths in three sites, viz. the Australian Cotton Research Institute, ACRI, near Narrabri $\left(149^{\circ} 36^{\prime} \mathrm{E}, 30^{\circ} 12^{\prime} \mathrm{S}\right)$, and two cotton farms near Wee Waa $\left(149^{\circ} 27^{\prime} \mathrm{E}\right.$, $\left.30^{\circ} 13^{\prime} \mathrm{S}\right)$ and Merah North $\left(149^{\circ} 18^{\prime} \mathrm{E}, 30^{\circ} 12^{\prime} \mathrm{S}\right)$ in northern New South Wales, Australia (Fig. 1). These sites have a sub-tropical, semi-arid climate (Kottek et al., 2006) with four distinct climatic seasons with a mild winter and a hot summer. The hottest month is January (mean daily maxima and minima of $34^{\circ} \mathrm{C}$ and $19^{\circ} \mathrm{C}$, respectively), whereas July is the coldest (mean daily maxima and minima $18^{\circ} \mathrm{C}$ and $3^{\circ} \mathrm{C}$, respectively). The soils were alkaline, self-mulching grey Vertisols, and classified as fine, thermic, smectitic, Typic Haplustersts (Soil Survey Staff, 2010). The ACRI site (average clay content in the 0-1.2 m depth was $62 \mathrm{~g} / 100 \mathrm{~g}$, ESP 5, soil organic carbon (SOC) 0.53 $\mathrm{g} / 100 \mathrm{~g}$ ) was sown with a cotton-wheat rotation on permanent beds where wheat stubble was retained as in situ mulch. The Wee Waa site (average clay content in the 0-1.2 m depth was $61 \mathrm{~g} / 100$ g, ESP 4, SOC $0.57 \mathrm{~g} / 100 \mathrm{~g}$ ) was sown with a cotton-wheat rotation where stubble was incorporated. At the Merah North site (average clay content in the 0-1.2 m depth was $67 \mathrm{~g} / 100 \mathrm{~g}$, ESP 14, SOC $0.46 \mathrm{~g} / 100 \mathrm{~g}$ ), there were three cropping sequences, continuous cotton, cotton-wheat, and cotton-dolichos sown between 1993 and 2000. The three sequences were sown with cotton during the 2000-01 and 2002-03 growing seasons, wheat during 2001 winter and sorghum during the 2001-02 growing season with stubble being incorporated. Details of the experimental sites and their management have reported by Weaver et al. (2005). Detailed soil properties of these sites are shown in Table 1.

Soil was sampled before sowing and after harvest (2000-01, 2001-02, 2002-03 cotton seasons) along diagonal transects in each plot and cores taken to a depth of $1.2 \mathrm{~m}$ at $20 \mathrm{~m}$ intervals at the ACRI and at $40 \mathrm{~m}$ intervals in all other sites. The cores were divided into depths of: 0-0.3, 0.3-0.6, 0.6-0.9 and 0.9-1.2 $\mathrm{m}$. Soil samples (3) were also removed from the 0-1.2 $\mathrm{m}$ depth of the return water channel from the ACRI experimental site and an adjacent irrigated field. An additional sample taken from the 0.6 to 0.9 metre depth of the adjacent field to the ACRI site was analysed to ascertain the reliability of the procedure before commencing analysis on the remaining soil samples. This field 
was selected as it had been sprayed with endosulfan during November 2004. The samples (0-1.2 m) were taken from the adjacent field shortly thereafter and included two from the head ditch and one from the tail drain. A total of 211 soil samples from the three sites were analysed for OCPs. Samples taken from the 0-0.90 m depth at Merah North during 2000 were not analysed because a preliminary assessment of a subsample showed that OCP concentrations in more than $90 \%$ of the samples were not detected by our methodology.

\subsection{Analysis of OCPs}

Ten grams of air-dried soil $(<0.5 \mathrm{~mm})$ from the $0-0.3,0.3-0.6,0.6-0.9 \mathrm{~m}$ depths of the second and fifth core in each transect sampled during 2000 at ACRI and Wee Waa, and 2002 in all sites, and from the 0.9-1.2 m depth of the entire transect sampled during 2000, 2001, 2002 and 2003 in all

sites, were refluxed for two hours using Whatman $^{\circledR}$ cellulose extraction thimbles (single thickness with internal diameter $28 \mathrm{~mm} \times 120 \mathrm{~mm}$ external length) in a $250 \mathrm{ml}$ soxhlet (Babić et al. 1998; Cornejo et al., 2005). The extractants were measured with a GC-ECD (gas-chromatography electron-capture detector) each peak quantified using peak area integration. The extractant was injected with each run on the GC/ECD as well as a blank. The method for analysis of the extractant, EPA method 608 (EPA, 2007) is briefly summarised as follows: a $1 \mu l$ sample was injected in the split mode (20:1) into a HP6890 ${ }^{\circledR}$ GC/ECD with a HP-5 crosslinked 5\% PH ME Siloxane column (30 $\mathrm{m} \times 0.32 \mathrm{~mm}$ i.d., and $0.25 \mathrm{~mm}$ film thickness) with argon methane $10 \%$ as the carrier gas and nitrogen as the make-up gas. The GC/ECD conditions were: injector and detector temperature $230^{\circ} \mathrm{C}$ and $280^{\circ} \mathrm{C}$, respectively, initial oven temperature $155^{\circ} \mathrm{C}$ held for $2 \mathrm{~min}$, then ramped at $8^{\circ} \mathrm{C} / \mathrm{min}$ to $230^{\circ} \mathrm{C}$ and held at that temperature for $5 \mathrm{~min}$. The run time was 16.38 minutes per sample. This method resulted in a recovery rate of the order of $60 \%$ and values were adjusted accordingly.

A soil sample removed in November 2004 from the ACRI site, depth 0-0.3 m, was sent to a certified Government analytical laboratory for analysis of OCPs. The method of analysis was supercritical fluid extraction (SFE). The results were as follows: $\alpha$-endosulfan, $45 \mu \mathrm{g} / \mathrm{kg} ; \beta$ - 
endosulfan, $8545 \mu \mathrm{g} / \mathrm{kg}$; endosulfan sulphate, $14 \mu \mathrm{g} / \mathrm{kg}$; DDE, $654 \mu \mathrm{g} / \mathrm{kg}$; DDD, $28 \mu \mathrm{g} / \mathrm{kg}$; DDT, $112 \mu \mathrm{g} / \mathrm{kg}$; endrin, $10 \mu \mathrm{g} / \mathrm{kg}$; dicofol, $18 \mu \mathrm{g} / \mathrm{kg}$; dieldrin, $10 \mu \mathrm{g} / \mathrm{kg}$. Dicofol and dieldrin were not analysed by our methodology.

\subsection{Soil analyses}

Air-dried soil ( $<2 \mathrm{~mm}$ diameter) was used to determine $\mathrm{pH}$ in a 1:5 soil:0.01 $\mathrm{M} \mathrm{CaCl}_{2}$ suspension, and $\mathrm{EC}_{1: 5}$, electrolytic conductivity in a 1:5 soil:water suspension (Rayment and Higginson, 1992). Exchangeable $\mathrm{Ca}, \mathrm{Mg}, \mathrm{K}$ and $\mathrm{Na}$ were measured with an atomic absorption spectrophotometer after washing with aqueous alcohol and aqueous glycerol to remove soluble salts followed by extraction with alcoholic $1 \mathrm{M} \mathrm{NH}_{4} \mathrm{Cl}$ at a $\mathrm{pH}$ of 8.5 (Tucker, 1985). Spectral lines used were $422.673 \mathrm{~nm}$ for $\mathrm{Ca}^{2+}, 285.213 \mathrm{~nm}$ for $\mathrm{Mg}^{2+}, 588.995 \mathrm{~nm}$ for $\mathrm{Na}^{+}$and $766.491 \mathrm{~nm}$ for $\mathrm{K}^{+}$(Tucker, 1985). The exchangeable cation concentrations were used to derive exchangeable sodium percentage, ESP (=Exchangeable $\mathrm{Na}^{*} 100 /$ Eexchangeable $\mathrm{Ca}, \mathrm{Mg}, \mathrm{K}, \mathrm{Na}$ ) and $\mathrm{EC}_{1: 5} / \mathrm{exch} . \mathrm{Na}$, both of which are indicators of soil structural stability, although the latter is reported to be superior (Hulugalle and Finlay, 2003). Total soil organic carbon (SOC) was determined by the wet oxidation method of Walkley and Black on air-dried soil $<0.5 \mathrm{~mm}$ diameter and nitrate-N with the Kjehdahl method (Rayment and Higginson, 1992).

\subsection{Statistical analyses}

The most persistent OCP detected was DDE, a degradation product of DDT; therefore DDE was modelled against factors depth, year and their interaction with site and sample location within site as blocking effects. Factors tillage, treatment, and crop phase were individually added to the model but dropped since they were not significant. The DDE data were loge transformed before statistical analysis to stabilize the variance. A linear model of log-transformed DDE data with explanatory variables exchangeable potassium, exchangeable calcium, exchangeable magnesium, exchangeable sodium, exchangeable sodium percentage (ESP) and $\mathrm{EC}_{1: 5}$ /exchangeable sodium content ratio was performed to show the relative amount of variation in $\log (\mathrm{DDE})$ explained by each of the soil properties. Using data obtained from all depths, a correlation analysis was 
performed between OCPs and soil properties. The OCP results ( $\alpha$-endosulfan, $\beta$-endosulfan, endosulfan sulphate, DDE and endrin) were analysed with analysis of variance for a repeated measures in time design with site as an explanatory variable to evaluate changes in concentrations from 2000 to 2003 . Values were transformed before analysis thus: $x^{\prime}=\operatorname{loge}(x+1)$ where $x$ is the untransformed value. A significance level of $10 \%$ was selected due to possible confounding with cropping system and variability in some of the data due to spatial and measurement variability.

\section{Results and discussion}

\subsection{Analysis Overview}

Of the 211 soil samples tested, 99\% contained detectable OCPs. The OCPs detected and their metabolites were $\alpha$-endosulfan, $\beta$-endosulfan, endosulfan sulphate, DDD, DDE, DDT and endrin (Figure 2). The OCP's tested for but not detected during this study were: aldrin, $\alpha$-BHC, $\beta$-BHC, $\gamma$ BHC (lindane), $\alpha$-chlordane, $\gamma$-chlordane, total chlordane, heptachlor and methoxychlor. The metabolite DDE, a breakdown product of DDT, with a half-life of 15 years (Shivaramaiah et al., 2002) had the highest concentration among OCPs at all depths analysed at ACRI, followed by endosulfan sulphate, $\alpha$-endosulfan and endrin. These OCP's were present at approximately similar concentrations. DDD concentrations were also relatively high in the surface $0.30 \mathrm{~m}$. $\beta$-endosulfan and DDT had the lowest concentrations at ACRI. DDT was sprayed extensively in the lower Namoi Valley for the control of Heliothis moths up to the early 1980's (Shivaramaiah et al., 2002) and may explain the persistence of DDE in a large number soil samples. In comparison with ACRI, endosulfan and its derivatives were found at concentrations greater than that of DDT at Wee Waa and Merah North (Table 2). DDT and endosulfan are no longer used by the Australian cotton industry. Changes occurred in concentrations of some OCPs between October 2000 and October 2002, presumably due to movement further into the soil profile (Table 2). These were DDE (P< 0.001), endrin $(\mathrm{P}=0.015), \alpha$-endosulfan $(\mathrm{P}=0.092)$ and endosulfan sulphate $(\mathrm{P}=0.063)$. 


\subsection{Endosulfan}

In general, endosulfan sulphate, $\alpha$-endosulfan and $\beta$-endosulfan concentrations were higher in the surface $0.6 \mathrm{~m}$ of both the ACRI and Wee Waa than at Merah North (Table 2). This is probably related to the frequency of endosulfan application in these sites. During the previous decade, endosulfan was rarely used at Merah North but was applied during most cotton seasons at both ACRI and Wee Waa. For instance, endosulfan 350EC was applied at Wee Waa on two occasions during this study. The first was on $1^{\text {st }}$ March 2002 at a rate of $2.1 \mathrm{~L} / \mathrm{ha}(350 \mathrm{~g}$ endosulfan/L) and the second was on $17^{\text {th }}$ December 2002 at the same rate. Soil was sampled 7 months after the first application and 5 months after the second application. At the ACRI endosulfan was applied at 2.1 L/ha on $28^{\text {th }}$ December 2001.

At Merah North, the most common OCP at the 0.9-1.2m depth was endosulfan sulphate followed by DDE (Table 2). The highest concentration of endosulfan sulphate detected was $76 \mu \mathrm{g} / \mathrm{kg}$ in the excotton-wheat sequence as compared to the ex-cotton-dolichos $(37 \mu \mathrm{g} / \mathrm{kg})$ and ex-continuous cotton (23 $\mu \mathrm{g} / \mathrm{kg})$. This may be related to movement of stubble, soil organic matter and aggregates down preferential flow pathways such as soil cracks, biopores and slickensides under dry conditions and with the wetting front during irrigation. This is consistent with the findings of Hulugalle et al. (2001) and Shivaramaiah el al. (2002) who surmised that the discovery of residues deeper in the soils of the Namoi Valley was the result of the downward movement of residues carried on dry soil into the cracks. Furthermore, the fibrous root system of wheat is reported to be able to dry out the soil to a greater extent, and thus form deeper cracks than the tap roots of crops such as cotton and dolichos (Hulugalle et al., 2006). The same authors also noted that specific volume of soil clods, extracted from bulk soil between cracks, was in the order of ex-cotton-wheat $>$ ex-continuous cotton $>$ excotton-dolichos. Given these differences in soil structural indices and thus, drainage (Weaver et al., 2005), it is not surprising that concentrations of endosulfan sulphate in the 0.9-1.2 $\mathrm{m}$ depth followed the same trend. Furthermore, as all three crop sequences were managed similarly with respect to pest management and irrigation, the lower concentrations of OCPs at depth under the ex-continuous 
cotton and ex-dolichos imply that larger amounts of OCPs may have been transported off-field via surface runoff. In contrast, the better structure and drainage in the ex-cotton-wheat may have resulted in smaller amounts being lost in runoff with larger amounts leached into the subsoil. Silburn et al. (2002) and Shivaramaiah et al. $(1998,2002)$ showed that OCPs such as endosulfan and DDE can be transported in runoff and eroded sediment from irrigated cotton fields. Silburn et al. (2002) suggested that the primary pathway of movement of endosulfan in soil was through the finer sediments while that of DDE was the more coarse aggregated sediments. This was because the aggregated sediments had higher organic matter content that adsorbed DDE and protected it from volatilisation, leaching and microbiological degradation (Silburn et al., 2002).

Degradation of $\alpha$-endosulfan results in an increase in endosulfan sulphate (Ghadiri and Rose, 2001). These authors also reported that soil moisture and temperature were the major determinants of the degradation rates of $\alpha$ and $\beta$ endosulfan isomers and their primary degradation product endosulfan sulphate. They found that when soil moisture levels and temperature are high $\alpha$-endosulfan had a half life of 7 days, whereas under cool, water stressed conditions it increased to 27 days. Under anaerobic conditions, which are characteristic of waterlogged soil or the deep subsoil of irrigated clay soils, however, the half life of $\alpha$-endosulfan increased to $\sim 50$ days. Under similar conditions, $\beta$ endosulfan had a half life of 87 days and endosulfan sulphate, 120 days. Consequently, under anaerobic conditions conversion rates of $\alpha$ and $\beta$ isomers of endosulfan to endosulfan sulphate was low, as was further degradation of the latter (Ghadiri and Rose 2001). In this study, endosulfan sulphate was observed at a depth of 1.2 metres at both Wee Waa and ACRI with decreases occurring at rates much higher than could be expected with degradation alone (Table 2). As deep tillage was not practiced in both these sites (an in Merah North) during the study period, we suggest that decrease in concentrations of endosulfan isomers and endosulfan sulphate in the deep subsoil can only be attributed to vertical movement via preferential flow systems such as cracks, biopores and slickensides while adsorbed onto clay particles and organic matter.

\subsection{DDT and DDE}


As noted in section 3.1, DDE was present at relatively high concentration at all depths in the ACRI and somewhat lower concentrations at Wee Waa and Merah North (Table 2). Between 2000 and 2003, however, concentrations decreased in the depths > 0.3 at Wee Waa and the ACRI, and in the 0.9-1.2 m depth at Merah North. Rates of decease in the 0.9-1.2 m depth was of the order of $7.4 \pm$ $3.0 \mu \mathrm{g} / \mathrm{kg} /$ year at ACRI and $2.6 \pm 1.3 \mu \mathrm{g} / \mathrm{kg} /$ year at WeeWaa. At Merah North, DDE concentrations under the ex-continuous cotton, ex-cotton-dolichos and ex-cotton-wheat decreased at rates of $1.9 \pm$ $0.9,1.8 \pm 0.4$ and $0.5 \pm 0.3 \mu \mathrm{g} / \mathrm{kg} /$ year. The relatively low values for ex-cotton-wheat was probably due to confounding by DDE from the upper horizons moving into this depth at faster rate than with the other rotations due to differences in soil structure (see section 3.2). Our results contradict those of Shivaramaiah et al. (1998) who reported that in the Gwydir and Macintyre valleys of NSW, DDE was only present in the surface $0.2 \mathrm{~m}$ and was not likely to move any deeper as they assumed that only lateral movement of water occurred in clayey Vertisols. However, deep drainage does occur in clayey Vertisols (Weaver et al., 2005; Ringrose-Voase and Nadelko, 2010). Thus, lipophilic pesticides that are adsorbed to organic carbon (Meijer et al., 2003; Cornejo et al., 2005) have the potential to move deeper into the soil profile.

The DDE concentrations of the order of $400 \mu \mathrm{g} / \mathrm{kg}$ in the surface $0.3 \mathrm{~m}$ at the ACRI are comparable to those reported by Gonzalez et al. (2010) for horticultural sites in Patagonia, Argentina, and Shivaramaiah et al. (2002) for cotton fields in Northern New South Wales, Australia, where heavy application rates of DDT were common in the past. The DDE concentrations in the surface $0.3 \mathrm{~m}$ at Wee Waa and Merah North were comparable to the lower range of values reported by Shivaramaiah et al. (2002) for the Namoi valley, in north western New South Wales, Australia that correspond to sites where DDT application rates were lower and less frequent. Youfeng et al. (2005) reported DDE residues in the deeper layers of soils that ranged from 0.4 to $5.4 \mu \mathrm{g} / \mathrm{kg}$. The range of DDE at 0.9-1.2 $\mathrm{m}$ in our study was from 0 to $33 \mu \mathrm{g} / \mathrm{kg}$. The higher maximum concentrations of DDE in our study probably reflects the higher rates and more frequent applications of DDT (Shivaramaiah et al., 2002) than in the study from China. 
There were no effects of treatment, cropping or tillage on DDE concentrations. However, the linear model (Table 3) indicated a strong association with organic carbon when compared to the other soil properties. Organic carbon was, thus, the soil property with the best linear relationship that could explain the change in DDE concentration. The linear relationships between DDE and soil organic carbon for the Wee Waa and ACRI sites are shown in Figure 3. There were strong correlations for these sites, although there were very poor correlations for the Merah North site. As deep tillage was not practiced during the study period at ACRI and Wee Waa, the close relationship between DDE and soil organic carbon suggests that, vertical movement of DDE into the deep subsoil was possibly due to transport via preferential flow systems such as cracks, biopores and slickensides while adsorbed onto organic matter. The high ESP values at Merah North may have resulted in greater dispersion leading to surface sealing and blocking of macropores by dispersed clay, and thus, less vertical preferential flow, and greater lateral and off-field movement of sediments, organic matter, and adsorbed DDE in runoff and erosion. Similar behaviour has been documented for Endosulfan in irrigated Vertisols of central Queensland in Australia (Kennedy et al., 2001). The relationship between organic carbon and DDT has been frequently studied although the results have been variable. Meijer et al. (2003) reported that hydrophobic chemicals like OCPs accumulated in the organic carbon fraction of soil, whereas others reported either no correlation (Zhu et al., 2005) or that organic carbon had no direct effect on the degradation of DDT (Zhang et al., 2006).

\subsection{OCPs and soil properties}

Except for DDT, which was not significantly related to any soil property, presumably because of its relatively low concentration (Table 2), some general trends were present with respect to correlations between OCPs and soil properties. Positive correlations were present for organic carbon, exchangeable $\mathrm{Ca}$ and $\mathrm{K}$, and $\mathrm{EC}_{1: 5} /$ exchangeable $\mathrm{Na}$, and negative correlations for exchangeable $\mathrm{Mg}$ and Na, and ESP (Table 3). OCPs are strongly adsorbed to soil organic matter (Meijer et al., 2003; Cornejo et al., 2005), and consequently, the positive relationship to soil organic carbon is not surprising (see also section 3.3 and Figure 3). Exchangeable $\mathrm{Ca}$ and $\mathrm{K}$ at the concentrations 
observed in this study, and $\mathrm{EC}_{1: 5} /$ exchangeable $\mathrm{Na}$ are known to be positively related to soil structural stability and permeability, whereas exchangeable $\mathrm{Mg}$ and $\mathrm{Na}$, and ESP are negatively related to the same (Chen et al., 1983; Sumner, 1993; Hulugalle and Finlay, 2003). Thus, in addition to organic matter, soil characteristics that enhance soil structure and permeability and, consequently, drainage, are likely to facilitate movement of OCPs deep into the subsoil of irrigated Vertisols.

\subsection{OCPs in return water channels and neighbouring fields}

The return water channel is used for all the fields irrigated at the research institute. Concentrations of DDD and DDE in the return water channel were, generally, higher than those in the adjacent field whereas the reverse occurred with respect to endosulfan sulphate and endosulfan isomers (Table 4). This was probably associated with historical chemical usage patterns and transport pathways. Silburn et al. (2002) suggested that erosion of fine sediments to which endosulfan had been adsorbed was the primary pathway of movement in soil while that of DDE was the coarse aggregated sediments, which protected it from volatilisation, and microbiological degradation. In our study, in-field DDE concentrations were lower than those in the return water channel because during the previous two decades DDT was not applied to cotton while eroded DDE-enriched sediments from all fields at the research station may have accumulated in the latter. In contrast, endosulfan was used during the study and concentrations were, thus, more likely to be higher in-field. At the same time, endosulfan that was transported into the tailwater channel may have been lost due to microbial degradation (Guerin, 1999) and volatilisation (Hose et al., 2003).

\subsection{Dicofol and dieldrin}

Dicofol is a non-systemic acaricide and has been used in agriculture and horticulture for the control of spider mites and soft-bodied mites in apples, cucumbers, tomatoes, hops, wines, lettuce and ornamentals. It is structurally similar to DDT and accumulates in body fat and is cumulative in the environment (Zhu et al 2005). The presence of DDT in human milk has been reported in China and the source of this contamination was thought to have come from the use of Dicofol, which contains 5-10\% DDT (Zhu et al. 2005). Dicofol has been applied in the past to control early season insect 
pests in cotton crops (Kennedy et al., 2000), although published research on the movement of Dicofol in Vertisols of the lower Namoi Valley in NSW appears to be non-existent.

Dieldrin is also a chlorinated hydrocarbon and was originally produced as an insecticide. It is an extremely persistent organic pollutant and is now banned in most of the world due to its proven toxicity to a wide range of animals including humans and it does not break down easily. It bioaccumulates as it is passes along the food chain. Its presence in the Vertisols at the ACRI is of concern as this too, had not been previously documented.

\section{Conclusions}

OCPs were present up to a depth of 1.2 metres in Vertisols of the lower Namoi Valley in NSW, Australia. Higher concentrations were observed under minimum-tilled cotton-wheat rotations, although significant differences were absent. In addition to more common OCPs such as DDE and endosulfan, previously undetected products such as dicofol and dieldrin were detected. The vertical movement of OCPs in Vertisols may occur when irrigation or rain transports soil colloids and organic matter via preferential flow systems into the deeper layers of a soil profile. Persistence of OCPs was closely correlated to soil organic carbon concentrations. The persistence in soil of OCP's applied to cotton crops grown more than two decades ago suggests that they could enter the food chain. Their presence at depths of $1.2 \mathrm{~m}$ suggests that they could move into groundwater that may eventually be used for domestic and stock consumption.

\section{Acknowledgements}

Funding for this research was provided by the Cotton Catchment Communities CRC, the Cotton Research \& Development Corporation and Griffith University. S. Burns and R. Diocares are thanked for their assistance with the pesticide analysis.

\section{References}

Babić, S., Kaštelan-Macan, M., Petrović, M., 1998. Determination of agrochemical combinations in spiked soil samples. Wat. Sci. Technol. 37, 243-250 
Chen, Y., Banin, A., Borchovitch, A., 1983. Effect of potassium on soil structure in relation to hydraulic conductivity. Geoderma 30, 135-147.

Cheng, Y., Pettry, D.E., 1993. Horizontal and vertical movements of two expansive soils in Mississippi. Soil Sci. Soc. Am. J. 57, 1542-1547.

Cornejo, J., Hermosin, M.C., Celis, R., Cox, L., 2005. Methods to determine sorption of pesticides and other organic compounds, in: Benedı, J.A., Munoz-Carpena, R., (Eds.), Soilwater-solute process characterization: an integrated approach. CRC Press, Boca Raton, FL, USA, pp. 435-464.

EPA (Environmental Protection Authority of the United States of America), 2007. Methods for organic chemical analysis of municipal and industrial wastewater: Method 608-Organochlorine pesticides and PCBs.

http://water.epa.gov/scitech/methods/cwa/organics/upload/2007_07_10_methods_method_orga nics_608.pdf (Accessed 10 February 2012).

Favre, F., Boivin, P., Wopereis, M.C.S., 1997. Water movement and soil swelling in a dry, cracked Vertisol. Geoderma 78, 113-123.

Feng, K.,Yu, B.Y., Ge, D.M., Wong, M.H., Wang, X.C., Cao, Z.H., 2003. Organo-chlorine pesticide DDT and $\mathrm{HCH}$ residues in the Taihu Lake Region and its movement in soil-water system I. Field survey of DDT and HCH residues in ecosystem of the region." Chemosphere $50,683-687$.

Ghadiri, H., Rose, C.W., 2001. Degradation of Endosulfan in a clay soil from cotton farms of western Queensland. J. Environ. Manage. 62, 155-169.

Gonzalez, M., Miglioranza, K.S.B., Aizpun, J.E., Isla, F. ., Pena, A., 2010. Assessing pesticide leaching and desorption in soils with different agricultural activities from Argentina Pampa and Patagonia. Chemosphere 813, 351-358.

Guerin, T., 1999. The anaerobic degradation of endosulfan by indigenous microorganisms from low-oxygen soils and sediments. Environ. Pollut. 106, 13-21. 
Haria, A.H., Johnson, A.C., Bell, J.P., Batchelor, C.H., 1994. Water movement and isoproturon behaviour in a drained clay soil: 1. Preferential flow processes. J. Hydrol. 163, 203-216.

Hose, G.C., Lim, R.P., Hyne, R.V., 2003. The transport, fate and effects of endosulfan in the Australian Freshwater environment. Aust. J. Ecotoxicol. 9, 101-111.

Hulugalle, N.R., Finlay, L.A., 2003. $\mathrm{EC}_{1: 5} /$ exchangeable Na, a sodicity index for cotton farming systems in irrigated and rainfed Vertosols. Aust. J. Soil Res. 41, 761-769.

Hulugalle, N.R., Weaver, T.B., Finlay, L.A., 2006. Residual effects of cotton-based crop rotations on soil properties of irrigated Vertosols in central-western and north-western New South Wales. Aust. J. Soil Res. 44, 467-477.

Hulugalle, N.R., Weaver, T.B., Finlay, L.A., Entwistle, P.C., 2001. Physical and chemical properties of soil near cracks in irrigated Vertisols sown with cotton-wheat rotations. Arid Land Res. Manag. 15, 13-22.

Kennedy, I.R., Sánchez-Bayo, F., Caldwell, R.A., 2000. Cotton Pesticides in Perspective: A discussion paper regarding research on pesticide management for the cotton industry. CRC for Sustainable Cotton Production, University of Sydney, Sydney, NSW, Australia, 75 pp. http://www.bashanfoundation.org/ivan/ivancottonindustry.pdf. Accessed 13 July 2011.

Kennedy, I.R., Sánchez-Bayo, F., Kimber, S.W., Hugo, L., Ahmad, N., 2001. Off-Site movement of Endosulfan from irrigated cotton in New South Wales. J. Enviro. Qual. 30, 683-696

Kishne, A.S., Morgan, C.L.S., Miller, W.L,. 2009. Vertisol crack extent associated with gilgai and soil moisture in the Texas Gulf Coast Prairie. Soil Sci. Soc. Am. J. 734, 1221-1230.

Kottek, M., Grieser, J., Beck, C., Rudolf, B., Rubel, F., 2006. World Map of the Köppen-Geiger climate classification updated. Meteorol. Z. 15, 259-263.

Meijer, S.N., Shoeib, M., Jones, K.C., Harner, T. 2003. Air-soil exchange of organochlorine pesticides in agricultural soils. 2. Laboratory measurements of the soil-air partition coefficient. Environ. Sci. Technol. 37, 1300-1305. 
Rayment, G.E., Higginson, F.R., 1992. Australian Laboratory Handbook of Soil and Water Methods, 1st ed. Inkata, Melbourne and Sydney, $330 \mathrm{p}$.

Ringrose-Voase, A., Nadelko, A., 2010. Deep drainage in a Vertosol under irrigated cotton, in: Gilkes, R., Prakongkep, N. (Eds.), Soil Solutions for a Changing World, Proc. $19^{\text {th }}$ World Congress of Soil Science, 1 - 6 August 2010, Brisbane, Australia, ISSS, Brisbane, Qld., Australia, pp. 27-30. [DVD]

Shivaramaiah, H.M., Odeh, I.O., Kennedy, I.R. Skerritt, J.H., 1998 Analysis of the distribution of DDT residues in soils of the Macintyre and Gwydir valleys of New South Wales, Australia using ELISA, in: Kennedy, I.R., Skerritt, J.H., Johnson, G.I., Highley, E. (Eds.), Seeking Agricultural Produce Free of Pesticide Residues. ACIAR, Canberra, ACT, Australia, pp. 386392.

Shivaramaiah, H.M., Odeh, I.O.A., Kennedy, I.R., Skerritt, J.H., 2002. Mapping the distribution of DDT residues as DDE in the soils of the irrigated regions of Northern New South Wales, Australia using ELISA and GIS. J. Agr. Food Chem. 50, 5360 -5367

Silburn, D.M., Montgomery, J., 2004, Deep drainage under irrigated cotton in Australia-A review, in "WATERpak a guide for irrigation management in cotton, section 2.4. Cotton Research and Development Corporation/Australian Cotton Cooperative Research Centre, Narrabri, NSW, Australia.

Silburn, D.M., Simpson, B.W., Hargreaves, P.A., 2002. Management practices for control of runoff losses from cotton furrows under storm rainfall. II. Transport of pesticides in runoff." Aust. J. Soil Res. 40, 21-44.

Soil Survey Staff, 2010. Keys to Soil Taxonomy. NRCS, USDA, Washington, D.C., USA, 338 pp. Sumner, M.E., 1993. Sodic soils: new perspectives. Aust. J. Soil Res. 31, 683-750.

Tucker, B.M., 1985. Laboratory procedures for soluble salts and exchangeable cations in soils, CSIRO Australia Div. Soils Tech. Paper no. 47, CSIRO, Canberra, 36 p.. 
Weaver, T.B., Hulugalle, N.R., Ghadiri, H., 2005. Comparing deep drainage estimated with transient and steady state assumptions in irrigated Vertisols. Irrig. Sci. 234, 183-191.

Youfeng, Z., Hui, L., Zhiqun, X., Hangxing, C., Xiaobai, X., 2005. Organochlorine pesticides DDTs and HCHs in soils from the outskirts of Beijing, China. Chemosphere 60, 770-778.

Zhang, H.B., Luo, Y.M., Zhao, Q.G., Wong, M.H., Zhang, G.L., 2006. Residues of organochlorine pesticides in Hong Kong soils. Chemosphere 63, 633-641.

Zhang, N., Yang, Y., Tao, S., Liu, Y., Shi, K.L., 2009. Burden and depth distribution of organochlorine pesticides in the soil profiles of Yangtze River Delta Region, China: Implication for sources and vertical transportation. Geoderma 153, 69-75.

Zhu, Y.F., Liu, H., Xi, Z.Q., Cheng, H.X., Xu, X.B., 2005. Organochlorine pesticides DDTs and HCHs in soils from outskirts of Beijing, China. Chemosphere 60, 700-778. 


\section{Namoi CMA Catchment Map}

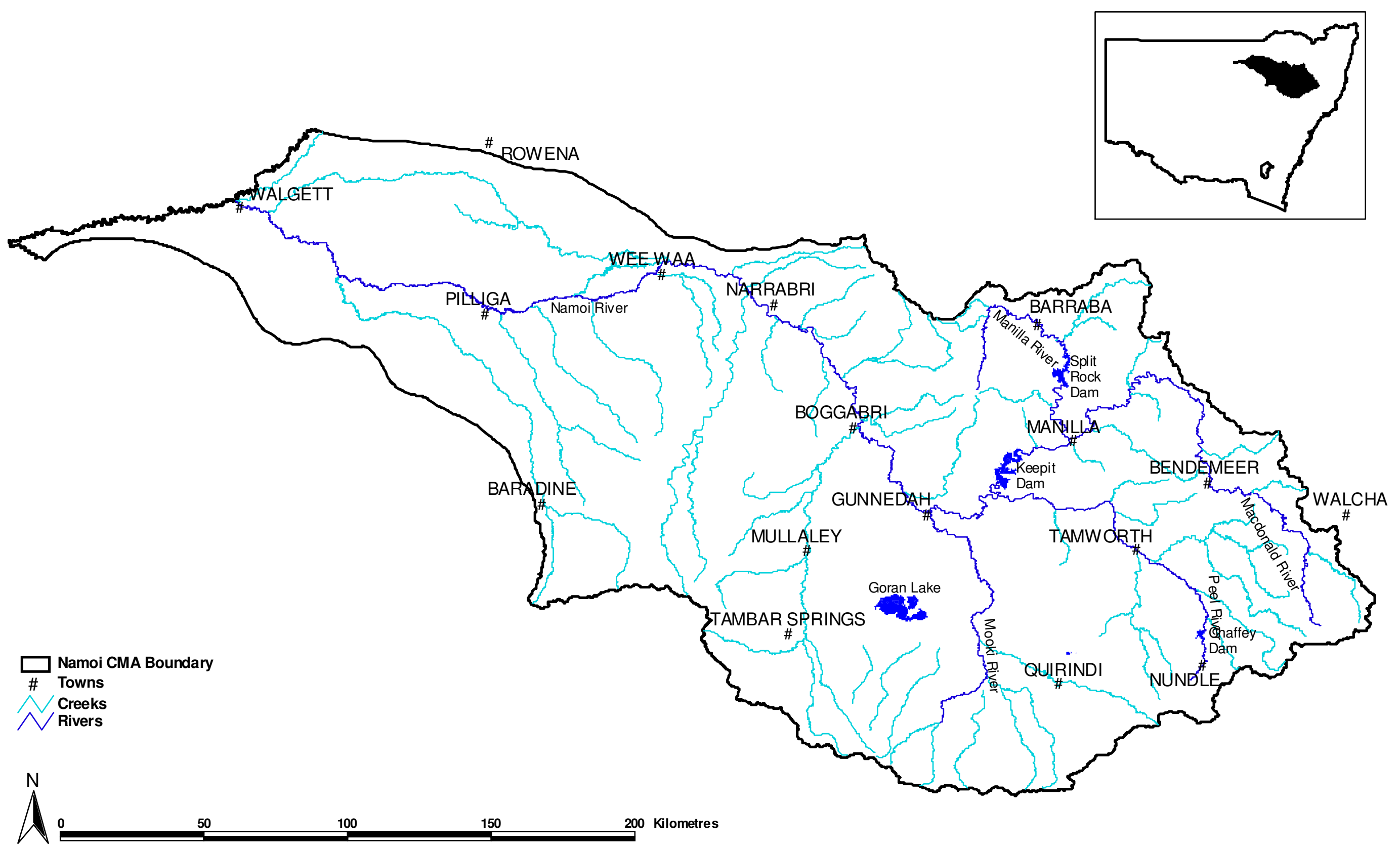

Fg 1. Map of Namoi Valley in New South Wales, A ustralia, showing the experimental sites at the ACRI near Narrabri, Wee Waa and Merah North. ( Source: Namoi Catchment Management A uthority, 2006; http://www.namoi.cma.nsw.gov.au/1namoi_catchment_map_feb06.pdf, accessed 13 July 2011) 
Table 1. Selected soil properties of the experimental sites. $\mathrm{pH}$ was measured in a 1:5 soil:0.01 M $\mathrm{CaCl}_{2}$ suspension; ESP, exchangeable sodium percentage; $\mathrm{EC}_{1: 5}$, electrical conductivity of a 1:5 soil:water suspension; SOC, soil organic carbon.

\begin{tabular}{lllllllll}
\hline Site & Depth $(\mathrm{m})$ & $\begin{array}{l}\text { Sand } \\
(\mathrm{g} / 100 \mathrm{~g})\end{array}$ & $\begin{array}{l}\text { Silt } \\
(\mathrm{g} / 100 \mathrm{~g})\end{array}$ & $\begin{array}{l}\text { Clay } \\
(\mathrm{g} / 100 \mathrm{~g})\end{array}$ & $\begin{array}{l}\mathrm{ESP} \\
\mathrm{pH}\end{array}$ & $\begin{array}{l}\mathrm{EC}_{1: 5} \\
(\mathrm{dS} / \mathrm{m})\end{array}$ & $\begin{array}{l}\text { SOC } \\
(\mathrm{g} / 100 \mathrm{~g})\end{array}$ \\
\hline ACRI, Narrabri & $0-0.30$ & 26 & 13 & 61 & 2 & 7.3 & 0.18 & 0.71 \\
& $0.30-0.60$ & 27 & 11 & 62 & 4 & 7.5 & 0.18 & 0.54 \\
& $0.60-0.90$ & 29 & 10 & 61 & 6 & 7.6 & 0.21 & 0.48 \\
& $0.90-1.20$ & 25 & 10 & 65 & 6 & 7.6 & 0.23 & 0.40 \\
\hline Wee Waa & $0-0.30$ & 27 & 13 & 60 & 3 & 7.2 & 0.22 & 0.72 \\
& $0.30-0.60$ & 28 & 12 & 60 & 4 & 7.4 & 0.2 & 0.62 \\
& $0.60-0.90$ & 26 & 12 & 62 & 5 & 7.5 & 0.24 & 0.51 \\
\hline Merah North & $0.90-1.20$ & 27 & 12 & 61 & 5 & 7.5 & 0.25 & 0.43 \\
\hline ex-Continuous & $0-0.30$ & 24 & 12 & 64 & 6 & 7.4 & 0.3 & 0.68 \\
Cotton & $0.30-0.60$ & 22 & 10 & 68 & 11 & 7.5 & 0.56 & 0.50 \\
& $0.60-0.90$ & 21 & 10 & 69 & 15 & 7.5 & 0.39 & 0.42 \\
& $0.90-1.20$ & 22 & 10 & 68 & 16 & 7.5 & 0.4 & 0.43 \\
\cline { 2 - 5 } & & & & & & & &
\end{tabular}




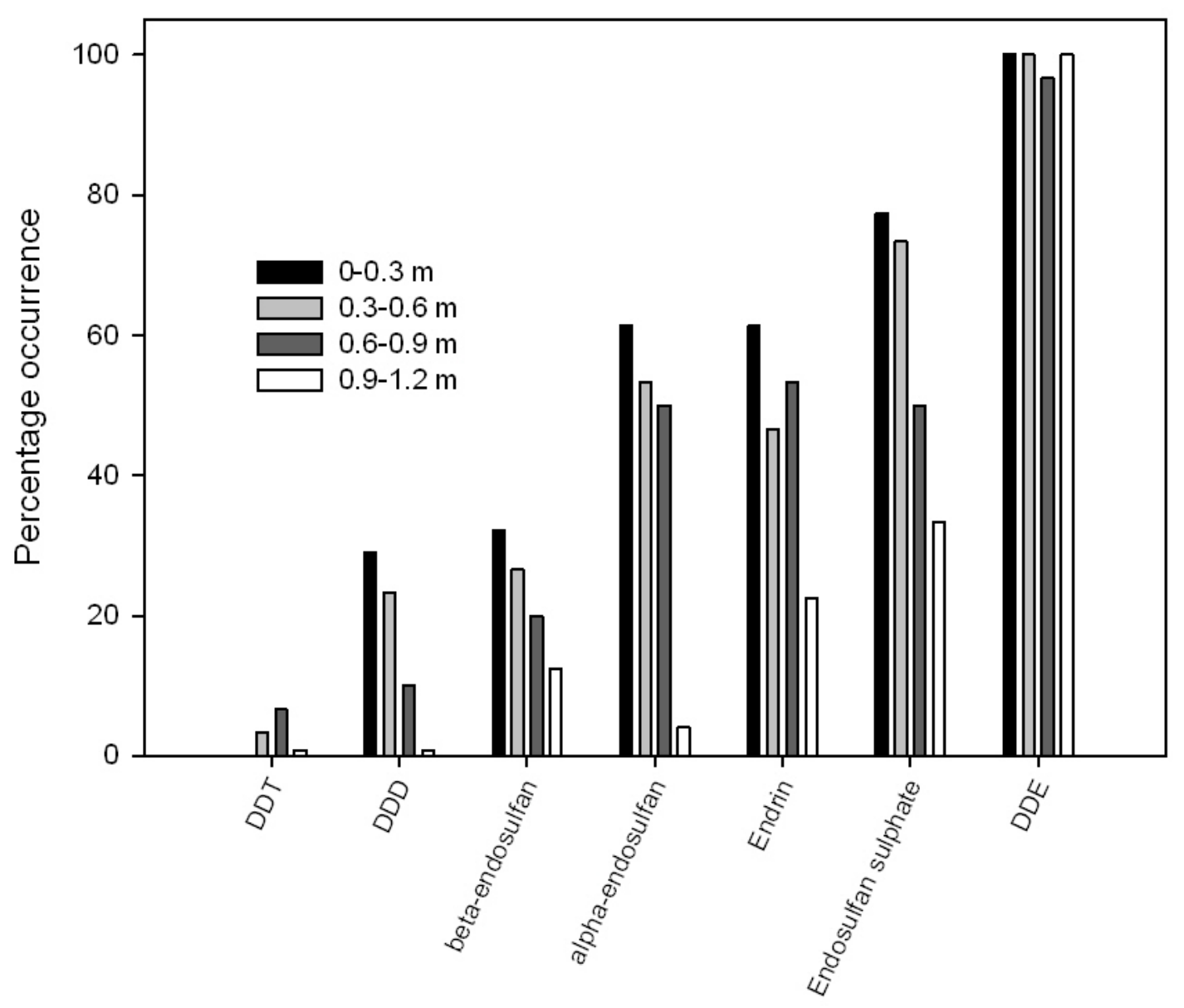

Fig. 2. Percentage occurrences of OCPs in samples taken from the ACRI, Wee Waa and Merah North experimental sites. 
Table 2. Average ( \pm standard deviation) OCP concentrations under cotton-based farming systems at the ACRI (Australian Cotton Research Institute),

Wee Waa and Merah North.

\begin{tabular}{|c|c|c|c|c|c|c|c|c|c|c|}
\hline \multirow[t]{2}{*}{ Site } & \multirow[t]{2}{*}{ Cropping system } & \multirow[t]{2}{*}{ Depth (m) } & \multirow[t]{2}{*}{ Year } & \multirow[t]{2}{*}{ Endrin } & DDD & DDT & DDE & $\alpha$-endosulfan & $\beta$-endosulfan & Endosulfan sulphate \\
\hline & & & & & \multicolumn{6}{|c|}{$\mu \mathrm{g} / \mathrm{kg}$} \\
\hline \multirow[t]{10}{*}{ ACRI } & Cotton-wheat & $0-0.30$ & 2000 & $53 \pm 18$ & $70 \pm 39$ & $0 \pm 0$ & $418 \pm 29$ & $83 \pm 22$ & $63 \pm 89$ & $50 \pm 16$ \\
\hline & & & 2002 & $31 \pm 5$ & $54 \pm 8$ & $0 \pm 0$ & $427 \pm 16$ & $77 \pm 11$ & $0 \pm 0$ & $79 \pm 24$ \\
\hline & & $0.30-0.60$ & 2000 & $27 \pm 9$ & $22 \pm 31$ & $0 \pm 0$ & $129 \pm 122$ & $48 \pm 2$ & $0 \pm 0$ & $33 \pm 26$ \\
\hline & & & 2002 & $6 \pm 5$ & $11 \pm 13$ & $0 \pm 0$ & $108 \pm 41$ & $25 \pm 3$ & $11 \pm 10$ & $21 \pm 10$ \\
\hline & & $0.60-0.90$ & 2000 & $53 \pm 61$ & $3 \pm 4$ & $8 \pm 11$ & $55 \pm 2$ & $75 \pm 79$ & $15 \pm 22$ & $16 \pm 10$ \\
\hline & & & 2002 & $2 \pm 4$ & $0 \pm 0$ & $0 \pm 0$ & $16 \pm 5$ & $0 \pm 0$ & $0 \pm 0$ & $4 \pm 7$ \\
\hline & & $0.90-1.20$ & 2000 & $8 \pm 6$ & $0 \pm 0$ & $0 \pm 0$ & $33 \pm 29$ & $7 \pm 12$ & $2 \pm 4$ & $20 \pm 36$ \\
\hline & & & 2001 & $1 \pm 2$ & $0 \pm 0$ & $0 \pm 0$ & $15 \pm 8$ & $0 \pm 0$ & $0 \pm 0$ & $12 \pm 23$ \\
\hline & & & 2002 & $0 \pm 0$ & $0 \pm 0$ & $0 \pm 0$ & $5 \pm 1$ & $0 \pm 0$ & $0 \pm 0$ & $2 \pm 5$ \\
\hline & & & 2003 & $4 \pm 10$ & $0 \pm 0$ & $0 \pm 0$ & $12 \pm 10$ & $0 \pm 0$ & $7 \pm 11$ & $10 \pm 16$ \\
\hline \multirow[t]{7}{*}{ Wee Waa } & Cotton-wheat & $0-0.30$ & 2000 & $20 \pm 1$ & $0 \pm 0$ & $0 \pm 0$ & $18 \pm 13$ & $30 \pm 8$ & $44 \pm 29$ & $33 \pm 13$ \\
\hline & & & 2002 & $0 \pm 0$ & $0 \pm 0$ & $0 \pm 0$ & $25 \pm 3$ & $29 \pm 4$ & $22 \pm 32$ & $10 \pm 14$ \\
\hline & & $0.30-0.60$ & 2000 & $131 \pm 172$ & $18 \pm 25$ & $7 \pm 10$ & $17 \pm 12$ & $39 \pm 12$ & $14 \pm 20$ & $15 \pm 7$ \\
\hline & & & 2002 & $0 \pm 0$ & $7 \pm 10$ & $0 \pm 0$ & $5 \pm 2$ & $35 \pm 50$ & $0 \pm 0$ & $9 \pm 13$ \\
\hline & & $0.60-0.90$ & 2000 & $48 \pm 31$ & $0 \pm 0$ & $0 \pm 0$ & $15 \pm 10$ & $34 \pm 4$ & $13 \pm 18$ & $14 \pm 5$ \\
\hline & & & 2002 & $4 \pm 5$ & $0 \pm 0$ & $0 \pm 0$ & $5 \pm 4$ & $10 \pm 14$ & $7 \pm 10$ & $17 \pm 24$ \\
\hline & & $0.90-1.20$ & 2000 & $11 \pm 13$ & $0 \pm 0$ & $0 \pm 0$ & $10 \pm 2$ & $0 \pm 0$ & $4 \pm 9$ & $33 \pm 41$ \\
\hline
\end{tabular}




\begin{tabular}{|c|c|c|c|c|c|c|c|c|c|c|}
\hline & & & 2001 & $2 \pm 4$ & $0 \pm 0$ & $0 \pm 0$ & $15 \pm 13$ & $0 \pm 0$ & $2 \pm 4$ & $31 \pm 55$ \\
\hline & & & 2002 & $0 \pm 0$ & $0 \pm 0$ & $0 \pm 0$ & $5 \pm 2$ & $0 \pm 0$ & $3 \pm 8$ & $6 \pm 8$ \\
\hline & & & 2003 & $13 \pm 15$ & $0 \pm 0$ & $0 \pm 0$ & $4 \pm 3$ & $0 \pm 0$ & $30 \pm 39$ & $6 \pm 10$ \\
\hline Merah North & Ex-cotton-cotton & $0-0.30$ & 2000 & - & - & - & - & - & - & - \\
\hline & & & 2002 & $3 \pm 5$ & $0 \pm 0$ & $0 \pm 0$ & $5 \pm 2$ & $0 \pm 0$ & $0 \pm 0$ & $0 \pm 0$ \\
\hline & & $0.30-0.60$ & 2000 & - & - & - & - & - & - & - \\
\hline & & & 2002 & $0 \pm 0$ & $0 \pm 0$ & $0 \pm 0$ & $6 \pm 2$ & $0 \pm 0$ & $0 \pm 0$ & $4 \pm 6$ \\
\hline & & $0.60-0.90$ & 2000 & - & - & - & - & - & - & - \\
\hline & & & 2002 & $0 \pm 0$ & $0 \pm 0$ & $0 \pm 0$ & $5 \pm 2$ & $53 \pm 12$ & $0 \pm 0$ & $0 \pm 0$ \\
\hline & & $0.90-1.20$ & 2000 & $0 \pm 0$ & $0 \pm 0$ & $0 \pm 0$ & $11 \pm 10$ & $0 \pm 0$ & $0 \pm 0$ & $1 \pm 3$ \\
\hline & & & 2001 & $1 \pm 2$ & $0 \pm 0$ & $0 \pm 0$ & $5 \pm 1$ & $0 \pm 0$ & $0 \pm 0$ & $23 \pm 38$ \\
\hline & & & 2002 & $1 \pm 2$ & $0 \pm 0$ & $0 \pm 0$ & $4 \pm 1$ & $0 \pm 0$ & $2 \pm 4$ & $2 \pm 4$ \\
\hline & & & 2003 & $0 \pm 0$ & $0 \pm 0$ & $0 \pm 0$ & $5 \pm 2$ & $0 \pm 0$ & $6 \pm 16$ & $4 \pm 10$ \\
\hline & Ex-cotton-dolichos & $0-0.30$ & 2000 & - & - & - & - & - & - & - \\
\hline & & & 2002 & $3 \pm 5$ & $0 \pm 0$ & $0 \pm 0$ & $6 \pm 0$ & $0 \pm 0$ & $0 \pm 0$ & $8 \pm 1$ \\
\hline & & $0.30-0.60$ & 2000 & - & - & - & - & - & - & - \\
\hline & & & 2002 & $0 \pm 0$ & $0 \pm 0$ & $0 \pm 0$ & $5 \pm 0$ & $0 \pm 0$ & $0 \pm 0$ & $11 \pm 15$ \\
\hline & & $0.60-0.90$ & 2000 & - & - & - & - & - & - & - \\
\hline & & & 2002 & $5 \pm 6$ & $0 \pm 0$ & $0 \pm 0$ & $5 \pm 3$ & $0 \pm 0$ & $0 \pm 0$ & $16 \pm 23$ \\
\hline & & $0.90-1.20$ & 2000 & $2 \pm 4$ & $0 \pm 0$ & $0 \pm 0$ & $7 \pm 1$ & $0 \pm 0$ & $5 \pm 12$ & $21 \pm 35$ \\
\hline & & & 2001 & $0 \pm 0$ & $0 \pm 0$ & $0 \pm 0$ & $5 \pm 1$ & $0 \pm 0$ & $2 \pm 4$ & $37 \pm 66$ \\
\hline & & & 2002 & $3 \pm 4$ & $0 \pm 0$ & $0 \pm 0$ & $4 \pm 1$ & $0 \pm 0$ & $0 \pm 0$ & $7 \pm 23$ \\
\hline & & & 2003 & $0 \pm 0$ & $0 \pm 0$ & $0 \pm 0$ & $3 \pm 1$ & $0 \pm 0$ & $0 \pm 0$ & $1 \pm 3$ \\
\hline
\end{tabular}




\begin{tabular}{llllllllll}
\hline Ex-cotton-wheat & $0-0.30$ & 2000 & - & - & - & - & - & - & - \\
& & 2002 & $6 \pm 9$ & $0 \pm 0$ & $0 \pm 0$ & $5 \pm 2$ & $44 \pm 9$ & $6 \pm 9$ & $12 \pm 17$ \\
& $0.30-0.60$ & 2000 & - & - & - & - & - & - & - \\
& 2002 & $0 \pm 0$ & $0 \pm 0$ & $0 \pm 0$ & $4 \pm 3$ & $0 \pm 0$ & $0 \pm 0$ & $13 \pm 3$ \\
& \multirow{2}{*}{$0.60-0.90$} & 2000 & - & - & - & - & - & - & - \\
& 2002 & $6 \pm 9$ & $0 \pm 0$ & $0 \pm 0$ & $2 \pm 0$ & $0 \pm 0$ & $0 \pm 0$ & $0 \pm 0$ \\
& $0.90-1.20$ & 2000 & $0 \pm 0$ & $0 \pm 0$ & $0 \pm 0$ & $6 \pm 2$ & $4 \pm 9$ & $0 \pm 0$ & $45 \pm 107$ \\
& 2001 & $5 \pm 7$ & $0 \pm 0$ & $3 \pm 8$ & $5 \pm 1$ & $0 \pm 0$ & $0 \pm 0$ & $76 \pm 158$ \\
& 2002 & $0 \pm 0$ & $0 \pm 0$ & $0 \pm 0$ & $3 \pm 1$ & $0 \pm 0$ & $0 \pm 0$ & $3 \pm 17$ \\
& 2003 & $8 \pm 16$ & $3 \pm 6$ & $0 \pm 0$ & $8 \pm 4$ & $9 \pm 15$ & $8 \pm 21$ & $8 \pm 20$ \\
\hline
\end{tabular}


Table 3. Correlation coefficients between OCPs and soil variable. Data pooled across all sites, years and depths. Values $>|0.17|$ are significant at $\mathrm{P}<0.05$ and are indicated by the symbol '*'.

\begin{tabular}{|c|c|c|c|c|c|c|c|}
\hline Soil variable & Endrin & DDD & DDT & $\overline{\mathrm{DDE}}$ & $\alpha$-endosulfan & $\beta$-endosulfan & Endosulfan sulphate \\
\hline Clay & $-0.25 *$ & $-0.18^{*}$ & 0.05 & $-0.21 *$ & $-0.22 *$ & -0.13 & -0.15 \\
\hline Silt & 0.16 & 0.16 & -0.01 & 0.17 & $0.22 *$ & 0.14 & 0.16 \\
\hline Sand & $0.20 *$ & 0.11 & -0.05 & 0.14 & 0.13 & 0.07 & 0.08 \\
\hline $\mathrm{pH}_{1: 5}$ & 0.15 & 0.01 & 0.1 & 0.14 & 0.01 & -0.23 & -0.13 \\
\hline $\mathrm{EC}_{1: 5}$ & -0.17 & $-0.22 *$ & -0.07 & $-0.24 *$ & $-0.32 *$ & -0.12 & 0.01 \\
\hline $\mathrm{NO}_{3}-\mathrm{N}$ & -0.11 & -0.07 & -0.09 & -0.1 & -0.05 & -0.06 & $0.35 *$ \\
\hline Soil organic carbon & $0.28 *$ & $0.42 *$ & 0.07 & $0.46^{*}$ & $0.48^{*}$ & $0.29 *$ & $0.22 *$ \\
\hline Exchangeable $\mathrm{Ca}$ & $0.20 *$ & $0.30 *$ & 0.16 & $0.33 *$ & $0.37 *$ & $0.19 *$ & 0.10 \\
\hline Exchangeable Mg & $-0.49 *$ & $-0.55^{*}$ & -0.03 & $-0.61 *$ & $-0.56^{*}$ & $-0.30 *$ & $-0.27 *$ \\
\hline Exchangeable K & $0.22 *$ & $0.38 *$ & -0.01 & $0.51 *$ & $0.32 *$ & -0.02 & $0.20 *$ \\
\hline Exchangeable $\mathrm{Na}$ & $-0.34 *$ & $-0.29 *$ & -0.07 & $-0.34 *$ & $-0.40^{*}$ & $-0.21 *$ & -0.14 \\
\hline ESP & $-0.36^{*}$ & $-0.33^{*}$ & -0.08 & $-0.38 *$ & $-0.44 *$ & $-0.23 *$ & -0.15 \\
\hline $\mathrm{EC}_{1: 5} / \mathrm{exch} . \mathrm{Na}$ & $0.55 *$ & $0.47 *$ & -0.04 & $0.57 *$ & $0.47 *$ & $0.26 *$ & $0.33 *$ \\
\hline
\end{tabular}



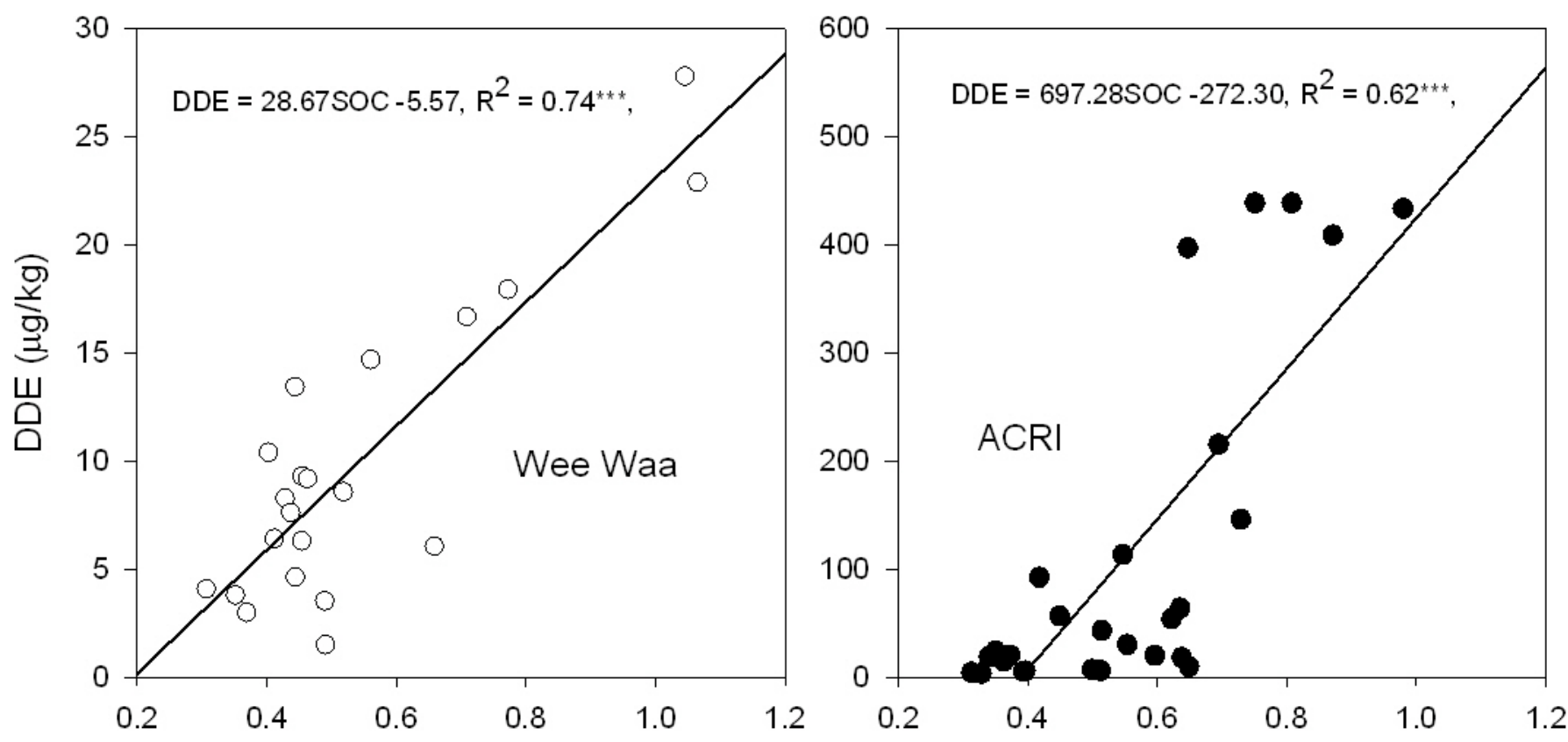

Soil organic carbon $(\mathrm{g} / 100 \mathrm{~g})$

Fig. 3. Variation of DDE with soil organic carbon concentration at the Wee Waa and ACRI experimental sites. 
Table 4. Average ( \pm standard deviation) OCP concentrations in return water channel and adjacent cotton field at ACRI (Australian Cotton Research Institute, Narrabri).

\begin{tabular}{|c|c|c|c|c|c|c|c|c|}
\hline \multirow[t]{2}{*}{ Site } & \multirow[t]{2}{*}{ Depth (m) } & Endrin & DDD & DDT & DDE & $\alpha$-endosulfan & $\beta$-endosulfan & Endosulfan sulphate \\
\hline & & & \multicolumn{6}{|c|}{$\mu \mathrm{g} / \mathrm{kg}$} \\
\hline \multirow[t]{4}{*}{ Return water channel } & $0-0.30$ & $3 \pm 5$ & $5 \pm 8$ & $0 \pm 0$ & $94 \pm 40$ & $8 \pm 5$ & $8 \pm 7$ & $34 \pm 26$ \\
\hline & $0.30-0.60$ & $1 \pm 2$ & $6 \pm 10$ & $17 \pm 10$ & $106 \pm 75$ & $7 \pm 6$ & $9 \pm 8$ & $24 \pm 9$ \\
\hline & $0.60-0.90$ & $4 \pm 3$ & $305 \pm 528$ & $36 \pm 8$ & $357 \pm 480$ & $15 \pm 15$ & $25 \pm 29$ & $139 \pm 203$ \\
\hline & $0.90-1.20$ & $2 \pm 3$ & $90 \pm 107$ & $76 \pm 66$ & $142 \pm 117$ & $7 \pm 6$ & $6 \pm 7$ & $65 \pm 5$ \\
\hline \multirow[t]{4}{*}{ Cotton field } & $0-0.30$ & $5 \pm 8$ & $3 \pm 4$ & $32 \pm 14$ & $142 \pm 33$ & $36 \pm 13$ & $121 \pm 25$ & $56 \pm 13$ \\
\hline & $0.30-0.60$ & $2 \pm 4$ & $4 \pm 7$ & $12 \pm 3$ & $88 \pm 44$ & $18 \pm 10$ & $68 \pm 34$ & $28 \pm 23$ \\
\hline & $0.60-0.90$ & $0 \pm 0$ & $0 \pm 0$ & $31 \pm 28$ & $54 \pm 27$ & $15 \pm 5$ & $46 \pm 26$ & $41 \pm 12$ \\
\hline & $0.90-1.20$ & $7 \pm 7$ & $0 \pm 0$ & $76 \pm 26$ & $58 \pm 50$ & $19 \pm 13$ & $41 \pm 44$ & $51 \pm 26$ \\
\hline
\end{tabular}


Scanned certificates of analyses from certified laboratories/manufacturers for soil reference material and pesticide mixtures used for standards.

\section{Certificate of Analysis}

\section{Organochlorine Pesticides Mixture}

Product Number: PPM-608B

Lot Number:

CA-1911

Expiration Date: Dec-2005

Page: $\quad 1$ of 1

This Certified Reference Material (CRM) was manufactured and verified in accordance with ULTRA's ISO 9001:2000 registered quality system, and the analyte concentrations were verified by our ISO 17025 accredited laboratory. The true value and uncertainty value at the $95 \%$ confidence level for each analyte,
determined gravimetrically, is listed below.

\begin{tabular}{llll} 
Analyte & \multicolumn{1}{c}{ CAS\# } & Analyte Lot & True Value \\
endosulfan II & $033213-65-9$ & $29494-55$ & $20.0 \pm 0.1 \mu \mathrm{g} / \mathrm{mL}$ \\
endosulfan sulfate & $001031-07-8$ & $32455-01$ & $20.0 \pm 0.1 \mu \mathrm{g} / \mathrm{mL}$ \\
endrin & $000072-20-8$ & $35053-09$ & $20.0 \pm 0.1 \mu \mathrm{g} / \mathrm{mL}$ \\
endrin aldehyde & $007421-93-4$ & $33381-04$ & $20.0 \pm 0.1 \mu \mathrm{g} / \mathrm{mL}$ \\
heptachlor & $000076-44-8$ & $33379-48$ & $20.0 \pm 0.1 \mu \mathrm{g} / \mathrm{mL}$ \\
aldrin & $000309-00-2$ & ER082003-01 & $20.0 \pm 0.1 \mu \mathrm{g} / \mathrm{mL}$ \\
alpha-BHC & $000319-84-6$ & CAP-27275-15 & $20.0 \pm 0.1 \mu \mathrm{g} / \mathrm{mL}$ \\
beta-BHC & $000319-85-7$ & $35072-32$ & $20.0 \pm 0.1 \mu \mathrm{g} / \mathrm{mL}$ \\
delta-BHC & 00031 y-86-8 & $9610 A$ & $20.0 \pm 0.1 \mu \mathrm{g} / \mathrm{mL}$ \\
gamma-BHC & $000058-89-9$ & NT01899 & $20.0 \pm 0.1 \mu \mathrm{g} / \mathrm{mL}$ \\
4,4'-DDD & $000072-54-8$ & $22599-62$ & $20.0 \pm 0.1 \mu \mathrm{g} / \mathrm{mL}$ \\
4,4'-DDE & $000072-55-9$ & $09020 K \mathrm{KU}$ & $20.0 \pm 0.1 \mu \mathrm{g} / \mathrm{mL}$ \\
4,4'-DDT & $000050-29-3$ & MD-101797 & $20.0 \pm 0.1 \mu \mathrm{g} / \mathrm{mL}$ \\
dieldrin & $000060-57-1$ & $35006-40$ & $20.0 \pm 0.1 \mu \mathrm{g} / \mathrm{mL}$ \\
endosulfan I & $000959-98-8$ & BCD-29550-56 & $20.0 \pm 0.1 \mu \mathrm{g} / \mathrm{mL}$ \\
heptachlor epoxide - isomer B & $001024-57-3$ & $31337-33$ & $20.0 \pm 0.1 \mu \mathrm{g} / \mathrm{mL}$
\end{tabular}

Matrix: methanol (methyl alcohol)

Balances used in the manufacture of this standard are calibrated with weights traceable to NIST in compliance with ANSI/NCSL Z-540-1 and ISO 9001

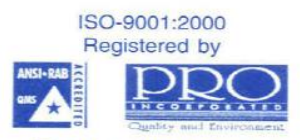

Reg. No. 00-R1192rev.1

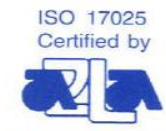

Cert. No. 0851-01
NOV 042004

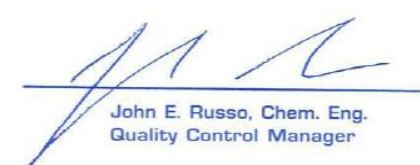

\section{ULTRA SCIENTIFIC}




\section{Certificate of Analysis}

NATURAL MATRIX CERTIFIED REFERENCE MATERIAL

\section{Catalog No: CRM809-050 \\ Lot No: AF809}

\section{PESTICIDES ON SOIL}

\section{ANALYTE CONCENTRATIONS}

Analyte

4,4'-DDD

4,4'-DDE

4,4'-DDT

Aldrin

alpha-BHC

beta- $\mathrm{BHC}$

gamma-BHC (Lindane)

alpha-chlordane

gamma-chlordane

Total Chlordane

Dieldrin

Endosulfan I

Endosulfan II

Endosulfan Sulfate

Endrin

Heptachlor

Methoxychlor $\begin{aligned} & \text { Reference } \\ & \text { Value }\end{aligned}$

480

346

376

159

394

308

430

(32.9)

45.4

(325)

287

362

361

378

408

177

330

S.D.
44.8
91.4
71.0
36.9
102
80.9
116

9.86

80.2
61.4
53.8
91.8
43.5
32.1
93.6

Confidence

interval

456- 505

$300-391$

$330-422$

$134-184$

$340-448$

266 - 351

366- 493

Prediction

Interval

$381-580$

$144-547$

217- 535

75.8- 242

168- 621

130- 487

173- 686

$39.1-51.7$

$22.5-68.3$

246- 328

322- 401

323- 398

$326-429$

$384-432$

155- 199

$281-380$

$110-464$

224- 499

239- 482

174- 581

312- 504

105- 249

123- 537

All values are expressed in $\mu \mathrm{g} / \mathrm{Kg}$ (parts per billion) on a dry weight basis. The Reference Values were determined by USEPA SW846 (3rd edition) method $8081 \mathrm{~A}$. The sample is suitable for this and other similar methods. The Confidence Interval (C.I.) range is the $95 \%$ C.l. for the Reference Value. The Prediction interval methods. The Confidence interval (C.I.) range is the times. (See Product Information Sheet for Details) The Certified Reference Values were established through extensive interlaboratory testing. All values were calculated using the USEPA BIWEIGHT Method.

"THIS PRODUCT WAS DESIGNED, PRODUCED AND VERIFIED FOR ACCURACY AND STABILITY IN ACCORDANCE WITH USEPA/AALA RM-03, ISO GUIDES 34 AND 35."

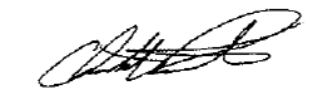

Certifying Officer
RESOURCE

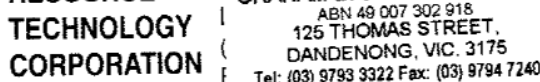


Table 1. Recovery of OCPs

\begin{tabular}{lrrrrrrrr}
\hline $\begin{array}{l}\text { Sample } \\
\text { size }\end{array}$ & Endrin & DDD & DDT & DDE & $\alpha$-endosulfan & $\beta$-endosulfan & $\begin{array}{l}\text { endosulfan } \\
\text { sulfate }\end{array}$ \\
\hline $10 \mathrm{~g}$ & 100 & 93 & 96 & 93 & 76 & 80 & 67 \\
\hline
\end{tabular}

